\title{
Assessment of Patients' Needs Pre and Post Open Heart surgery
} Amal Mahmoud Abd El-gafour ${ }^{1}$,Gehan Abd ElHakemYounis', Sheren Mohammed Abed El-latief Gad ${ }^{3}$

\author{
${ }^{1}$ Bachelor of Nursing, Staff Nurse at Tanta Educational University Hospital \\ ${ }^{2}$ Assistant Professor of Critical Care Nursing, Faculty of Nursing, Tanta University \\ ${ }^{3}$ Lecturer of Critical Care Nursing, Faculty of Nursing, Tanta University
}

\begin{abstract}
Background: Assessment of Bio-psychosocial needs of patient pre and post open heart surgery are very important aspect of patient centered care. Aim: was to assess patients' needs pre and post Open Heart Surgery. Design: -A descriptive exploratory design was utilized in this study. Settings: This study was conducted at Cardio-Thoracic Intensive Care Unit of Educational Tanta University Hospital. Subjects: A convenience sample of (100) open heart surgery patients that had been admitted to Cardio-Thoracic Intensive Care unit and meeting the inclusion criteria. Tools of the study: Two tools was used in this study for data collection: Tool I:A structured Interview Schedule Tool II:Bio psychosocial Needs Interview Questionnaire which included three parts; part (1): Physical Needs for Patients undergoing Open Heart Surgery, part(2): Psychological Assessment for Patients with Open Heart Surgery and part (3) Social Dysfunction Rating Scale for Patients with Open Heart Surgery. Results: There was highly significant positive correlation between total Social Dysfunction of the studied patients and their total score of pain score and total score of psychological needs at $(\mathrm{P}=<0.01)$. In addition, there were significant positive correlation between total score of pain score of the studied patients and their total score of psychological needs and total score of Social Dysfunction at $(\mathrm{P}=<0.01)$. Conclusion: The study concluded that, three-quarters of the studied patient had unsatisfactory level of total knowledge about heart surgeries. Also, there was a marked increase in total patients' dependency in Activities of Daily Living level at post heart surgery. Recommendations: Routine pre and postoperative assessment of patients who are undergoing open heart surgery is recommended to identify the different patient's biopsychosocial needs and consequently any risk factor and reduced the post-operative complications.
\end{abstract}

Key words: - Bio-psychosocial needs, Open Heart Surgery 


\section{Introduction}

Open heart surgery is a surgery in which the chest is opened and surgery is done on the heart muscle, valves, arteries, or other parts of the heart. It is a major surgery that requires a hospital stay of a week or more. Open heart surgery Patient will spend time in the Intensive Care Unit immediately after surgery. It is done to allow blood to flow around blocked blood vessels in the heart $^{(1)}$.

Open heart surgeries such as coronary artery by bass graft (CABG) and valve replacements have been used to improve patient outcomes related to cardiac symptoms, prolongation of life, and healthrelated quality of life. Although these surgical outcomes are beneficial, research has suggested that the experience and recovery process after open-heart surgery may be more complex than anticipated and presents psychosocial and physical challenges that will continue after hospital discharge $e^{(2)}$.

According to statistics from Open Heart Surgery Department at Tanta University, patients admitted for open heart surgery are about 20 cases per month. Also, it was reported that about $53 \%$ of patients undergoing Coronary Artery Bypass Grafting (CABG) with cardiopulmonary Bypass (CPBG) had abnormal neurocognitive function at discharge, $24 \%$ of them continued to have neurologic abnormalities at 6 months after their cardiac surgery, and $42 \%$ reported cognitive decline at 5 years following the surgery $^{(3)}$. Delirium occurs in up to $10 \%$ of patients more than 65 years of age and is also associated with worse long- term mortality. Other early postoperative neurocognitive abnormalities occur in up to $60 \%$ of patients and manifest as mild deficits in memory, attention, concentration and language ${ }^{(4)}$.

Complications after open heart surgery include low cardiac output syndrome, arrhythmias, cardiac tamponade, or myocardial depression with or without myocardial necrosis, excessive bleeding can occur post operation or secondary to coagulopathy, uncontrolled hypertension and neuro-psychological dysfunction. The highest risk of postoperative central nervous system dysfunction is associated with long cardiopulmonary bypass (CPB) times, perioperative hypotension and postcardiotomy delirium that occurs 2 to 5 days after cardiac surgery and is manifested as mild confusion, somnolence, agitation, or hallucinations $^{(5)}$.

Assessing the needs for patients subjected to open heart surgery is very important to facilitate patient's recovery and helping them to cope with any problems. Post cardiac surgery neurologic outcomes focused on clinically obvious neurologic 
and psychological dysfunction such as stroke, disorientation, and depression ${ }^{(6)}$. However, with more widespread use of neuro-psychometric testing typically includes measures of language and memory, exercise and activity after open heart surgery are important for healthy healing and will help patients return to a more active lifestyle. Aerobic exercise is a continuous training that uses the large muscle groups to helps heart and lungs to work more efficiently. It also helps to control other risk factors for heart disease and stroke ${ }^{(7)}$.

The biopsychosocial assessment is a very important step in medical care as it broadens the scope with which health and illness can be examined in clinical practice, in the assessment, prevention and treatment of diseases especially in open heart surgery. Because it includes complicated procedures that require high qualified professionals with a unique skills such as coronary artery bypass, repair of damaged structures, and heart transplant, as well as other treatments such as implantation of medical devices. The role of the professional nurse in the pre and post-operative care of the patient undergoing open heart surgery is beneficial for obtaining a positive outcome for the patient $^{(8)}$.

\section{Significance of study:}

Triage and treatment of patients in Open Heart Surgery Department deserve first priority. However, biopsychosocial case complexity may also affect patient health outcome and not explored in this setting, therefore, the aim of the study is to estimate prevalence rates of biopsychosocial problems in patients undergoing open heart surgery to evaluate possible correlations between patient profiles regarding case complexity and further clinical treatment.

\section{Operational definitions of}

biopsychosocial patients' needs include assessment of the following needs: physical needs (pain assessment, basic activities of daily living as bathing, dressing, toileting, transferring, continence and feeding), psychological needs through Anxiety assessment for patients with open heart surgery and assess social needs through social dysfunction rating scale (self-stem, interpersonal system and performance system) for open heart surgery patients.

The aim of this study was to: - Assess patients' needs pre and post Open Heart Surgery.

Research question: - What are the patients' needs pre and post Open Heart Surgery? 


\section{Subjects and Method}

Study design: - A descriptive exploratory design was utilized in this study.

\section{Study settings: -}

This study was conducted at CardioThoracic Intensive Care Unit of Educational Tanta University Hospital. The hospital has one floor for CardioThoracic Intensive Care unit consist of 5 wards, each ward contains 3 beds. The capacity of the unit includes 15 beds.

\section{Study subjects:-}

A convenience sample of (100) open heart surgery patients that had been admitted to Cardio-Thoracic Intensive Care unit and meeting the inclusion criteria. The sample size calculation by power analysis based on patient's admission in the hospital per year (250 patients/year).It was calculated based on epidemiological information program based on the total patients per year according to review of Tanta main university hospital statistical record.

\section{Study tools:}

Two tools were used in this study to assess bio- psychosocial needs for patients undergoing open heart surgery as follow:

Tool I: A structured Interview Schedule: It was developed by the researcher in Arabic language after reviewed literature and was divided into three parts:

Part (A):- Socio-Demographic Characteristics of Patients pre and post Open Heart Surgery.
It was included data about age, sex, marital status, level of education, previous occupation, income, and number of children.

Part (B): Past and Current Medical and Surgical History of Patients under the Study:

It included data about chronic diseases, medication received, previous admission to the hospital, previous surgical intervention (type of operation and its duration) and family history.

\section{Part (C): Open Heart Surgery}

Knowledge for patients:

It included data aboutindication, complications, management, and discharge plan. It consists of 8 -items to assess knowledge for patients pre and post open heart surgery. The patient responds ranged from 0 (Don't know) to 1 (know). The total score was obtained by summing all items, which ranged from (0-8). Total score of patients' knowledge was categorized as follows:-Less than or equal $60 \%$ of the total knowledge score considered unsatisfactory level of knowledge and more than $60 \%$ of total score considered satisfactory level of knowledge.

Tool II: Bio psychosocial Needs Interview Questionnaire: ${ }^{(9-13)}$

It was developed by the researcher after reviewing related literature and it included the following parts:

Part (A):-Physical Needs for Patients 
undergoing Open Heart Surgery: It included:

\section{Pain Assessment Scale ${ }^{(9)}$ :}

Pain assessment for patients undergoing open heart surgery had been done by using a Likert scale. This scale was developed by Galer and Gammaiton 2003 and it was adapted by the researcher in this study. It consists of 20-item to assess perception and sensation of pain for patient undergoing open heart surgery. The patient responds ranged from 0 (No pain) to 10 (sever pain). The total score was obtained by summing all items, which ranged from (0-200).

\section{Total score categorized as follows:-}

- Zero considered no pain

- Less than or equal $30 \%$ of the total score it will be considered mild level of pain.

- $31-60 \%$ of the total score it will be considered moderate level of pain.

- More than $60 \%$ of the total score it will be considered sever pain.

\section{Katz Index of Independence in} Activities of Daily Living(Katz ADL)for Patients undergoing Open Heart Surgery $^{(10,11)}$ :

This scale was developed by Katz et al., (2007)and it was adapted by the researcher. It was used to assess physical needs for patient pre and post open heart surgery by measuring the basic activities of daily living. Katz ADL index measures the ability to conduct self-care. It consists of six-item instrument, which assess the independence or dependence in the activities of bathing, dressing, toileting, transferring, continence and feeding. Patients are scored yes/no for independence in each of the six functions. Scores ranged from 0-6, a score of 6 indicated full function, 4 indicated moderate impairment and 2 or less indicated severe functional impairment.

Part (B):-Psychological Assessment for Patients with Open Heart Surgery ${ }^{(12)}$ :

This part was used to assess psychological needs for open heart surgery patients by using zung scale for anxiety. It was developed by Zung 1996. It was adapted by the researcher in this study. It was a self-administered test which has 20 questions to assess psychological needs and anxiety level for the patient. The patient responds by using a Likert scale using a 4-point scale, ranging from 1 (none, or a little of the time) to 4 (most, or all of the time).

There are 20 questions with 15 increasing anxiety level questions and 5 decreasing anxiety questions. Total score was obtained by summing all items which ranged from (20-80) raw score .Then converting the total raw score to anxiety index on the conversion chart. Record the corresponding anxiety index which ranged from 25-100 score. Compared the anxiety 
index with the clinical interpretation chart as following:

Anxiety index score categorized as follows:-

-Blow 45 indicated normal range

$-45-59$ indicated mild to moderate anxiety levels

$-60-74$ indicated marked to severe anxiety levels

-75 and over indicated extreme anxiety levels

Part (C):-Social Dysfunction Rating Scale for Patients with Open Heart Surgery ${ }^{(13)}$ :

This scale was developed by Ian2006. It was adapted by the researcher in this study. It consisted of 20-items to assess social needs for open heart surgery patients. The patient responded by using a Likert scale that ranged from 1 (none) to 6 (very sever). The total score was obtained by summing all items, which is ranged from (20-120).

\section{Total scorecategorized as follows:-}

1- Less than or equal $60 \%$ of the total score it considered low level of social dysfunction.

2- More than $60 \%$ of the total score it considered High level of social dysfunction.

\section{Method}

The study was accomplished through the

following steps:

Administrative process:
1-An official hospital permission and written approval to carry out the study was obtained from the Dean of Faculty of Nursing to the manager of Cardio-Thoracic Intensive Care Unit of Educational Tanta University Hospital before conducting this study through official letters explaining the purpose of the study.

\section{2- Ethical consideration:}

- Informed and written consent was obtained from the study group after explanation of the aim of the study and assuring them confidentiality of collected data.

- Patients were informed that participation is voluntary and that they could withdraw at any time of the study.

- Privacy of the studied patients was maintained.

- Confidentiality and autonomy were

maintained by the use of code number instead of name.

\section{3- Tool development:}

The study tools were developed and translated into Arabic language by the researcher based on literature review, modified to suit the level of understanding of all subjects and were tested for translation by experts in English language.

\section{4- Validity of the tools:}

All tools were tested for face validity by five jury of experts in the field of MedicalSurgical Nursing and Critical Care Nursing 
at the Faculty of Nursing in Tanta University before conducting the study.

\section{5- Reliability of the tools.}

The study tools were tested for its reliability by using cronbach's alpha test, it was computed and it was found to be for structured interview schedule $=(0.71)$, Pain Assessment Scale $=(0.74)$, Katz Index of Independence in Activities of Daily Living $=(0.83)$, Psychological Assessment for Patients with Open Heart Surgery= (0.79) and finally for Social Dysfunction Rating Scale for Patients with Open Heart Surgery $=(0.81)$.

\section{6- A pilot study:-}

It was conducted before the actual study on $10 \%$ of the patients (10 patients), in order to test the clarity, feasibility and applicability of the different items of the developed tools .Modifications, rephrasing and some additional terms were done by the researcher before the main study, according to the experience gained from this pilot study. Data obtained from those patients were excluded and not included in the current study.

\section{7- Data collection}

- Data was collected from patient's sample who's met the study criteria.

- Data were collected over a period of 6 months, started from April 2020 to September 2020.
-The patients were interviewed individually using the previously mentioned data collection tools.

- The purpose of the study was explained by the researcher to each patient included in this study.

- Data were collected at two times: firstly, at preoperative phase. Secondly, at postoperative period from the second day of operation when patient become able to complete the interview sheet.

\section{8- The present study was conducted}

\section{through:}

\section{Assessment phase:}

This phase was concerned with obtaining an official permission to conduct the study. The tools of the study were prepared after reviewing the recent literature.

\section{Pre and post-operative assessment:}

- The researcher used Tool (I) A structured Interview Schedule at the first time of patient's admission for collection of patient's data and assessed the patient who met the inclusion criteria and was included in the study through three parts.

- In tool (I), each patient was assessed regarding socio-demographic data (age, sex, marital status, level of education, previous occupation, income, and number of children), past and current medical and surgical history (chronic diseases, medication received, previous admission 
to the hospital, previous surgical intervention, availability of health services and reasons of using it) and patients' knowledge regarding open heart surgery (indication, complications, management, and discharge plan).

- Also, the researcher used tool (II) to assess bio psychosocial needs for open heart surgery patients. Part (A) assessed physical needs (pain assessment, basic activities of daily living as bathing, dressing, toileting, transferring, continence and feeding), part (B) assessed psychological needs and part (C) used to assess social needs for open heart surgery patients.

\section{9-Statistical analysis of data:}

The study data were computerized and verified using the SPSS (Statistical Package For Social Science) version 20 to perform tabulation and statistical analysis. Quantitative data were summarized by the arithmetic mean and standard deviation. All statistical analysis was done using two tailed test and alpha error of $0.05 \mathrm{p}$ value less than or equal to 0.05 was considered to be statistically significant. Frequency tables and cross tabulations with percentages was used to illustrate the result of categorical data and tested by chi square $(\chi 2)$. Correlation analysis: Pearson correlation is used to test nature and strength of relation between three quantitative/ordinal variables. The sign of 'Vol. 22 No. 3 (Suppl), August $202 \overline{1}$ the coefficients indicates the nature of relation as follow: week correlation for $(r$ ) less than 0.25 , intermediate correlation for ( $r$ ) of value between $0.25-0.74$ and strong correlation for value between $0.75-0.99 .^{(14)}$

\section{Results}

\section{Table (1) shows the distribution of the} study patients according to their sociodemographic characteristics. In relation to age, less than half ( $46 \%$ ) of the studied patients ranged between 50-60 years with Mean \pm SD 52.4 \pm 3.15 year. Regarding to marital status, the majority $(80 \%)$ of the studied patients were married. Related to residence, more than half $(55 \%)$ of the studied patients living in rural areas. In addition, less than half (44\%) of the studied patients were working. While, two fifth $(40 \%)$ of them were not working. Concerning monthly income, it was observed that less than two-thirds $(62 \%)$ of the studied patients had insufficient monthly income.

Table (2) presents the distribution of the studied elderly according to their past and current health history. In relation to history of chronic diseases, it was observed that, all (100\%) studied patients had history of heart disease, also, two-thirds $(66 \%)$ of them had history of hypertension. Regarding previous admission to the hospital, the vast majority (95\%) of the studied patients admitted to the hospital 
previously. In addition, all (100\%) studied patients taken medication before.

Concerning history of surgery, two-thirds $(66 \%)$ of the studied patients didn't have surgical history. While, more than onethird $(34 \%)$ of the studied patient had surgical history and less than half (41.2\%) of them had history of appendectomy. Finally, this table revealed that, more than half $(55 \%)$ of the studied patients didn't have family history of cardiac problems. While, less than half $(45 \%)$ of the studied patient had family history of cardiac problems and more than one-third (37.8\%) of them were the father.

Table (3) revealed the distribution of the studied patients according to their total knowledge about heart surgeries. It was observed that, three-quarters $(75 \%)$ of the studied patient had unsatisfactory level of total knowledge about heart surgeries. While, one-quarter $(25 \%)$ of them had satisfactory level of total knowledge about heart surgeries.

Table (4) revealedthe distribution of the studied patients according to their total pain score at Post Open Heart Surgery. It was observed that, more than half $(56 \%)$ of the studied patients had moderate level of total pain score at Post Open Heart Surgery. Also, less than one-quarter (23\%) of them had mild level. While, less than one-fifth $(16 \%)$ of them had severe level.
Table (5) revealed the distribution of the studied patients according to their total Independency in Activities of Daily Living at Pre and Post Open Heart Surgery. It was observed that, there was a marked increase in total patients' dependency in Activities of Daily Living level at post heart surgery with highly statistically significant difference at $(\mathrm{P}=0.000)$ between pre- and post- heart surgery. As evidence, less than two-thirds (62\%) of the studied patients were full function at pre heart surgery. While, the majority (95\%) of them had severe level of impairment at post heart surgery.

Table (6) shows the distribution of the studied patients according to their total anxiety at Post Open Heart Surgery. It was observed that, more than half (54\%) of the studied patients had severe level of total anxiety score at post Open Heart Surgery. Also, less than one-quarter (24\%) of them had minimal to moderate level. While, more than one-tenth $(12 \%)$ of them had extremely severe level.

Table (7) reveals the distribution of the studied patients according to their total social dysfunction subscales at Post Open Heart Surgery. It was observed that, less than two-thirds (64\% and 62\%) of the studied patients had high level of self-system dysfunction and performance system dysfunction at post Open Heart 
Surgery. Also, more than half (58\%) of them had high level of interpersonal system dysfunction. Finally, in this table, it was observed that, three fifth $(60 \%)$ of the studied patients had high level of social dysfunction at post Open Heart Surgery. While, two fifth $(40 \%)$ of them had low level of social dysfunction at post Open Heart Surgery.

Table (8) showed the correlation between pain score, Independency in ADL, psychological needs and social post -Open Heart Surgery. The table showed that, there was highly significant positive correlation between total Social Dysfunction of the studied patients and their total score of pain score and total score of psychological needs at $(\mathrm{P}=<0.01)$. In addition, there was significant positive correlation between total score of pain score of the studied patients and their total score of psychological needs and total score of Social Dysfunction at $(\mathrm{P}=<0.01)$. Also, there was significant negative correlation between total pain score of the studied patients and their Total score of Independency in $\mathrm{ADL}$ at $(\mathrm{P}=<0.01)$.In addition, there was highly significant negative correlation between total score of Independency in ADL of the studied patients and their total score of psychological needs and total score of Social Dysfunctional $(\mathrm{P}=<0.01)$. Also, there was significant positive correlation between total psychological needs of the studied patients and their Total score of Social Dysfunction at $(\mathrm{P}=<0.01)$. 
Table (1): Distribution of the studied patients according to their socio-demographic characteristics

\begin{tabular}{|c|c|c|}
\hline \multirow[t]{2}{*}{ Socio-demographic characteristics } & \multicolumn{2}{|c|}{$\begin{array}{c}\text { The studied } \\
\text { patients }(n=100)\end{array}$} \\
\hline & $\mathbf{N}$ & $\%$ \\
\hline \multicolumn{3}{|l|}{ Age (year) } \\
\hline $20-<30$ & 8 & 8.0 \\
\hline $30-<40$ & 16 & 16.0 \\
\hline $40-<50$ & 30 & 30.0 \\
\hline $50-60$ & 46 & 46.0 \\
\hline Range & \multirow{2}{*}{\multicolumn{2}{|c|}{$\begin{array}{c}21-60 \\
52.4 \pm 3.15\end{array}$}} \\
\hline Mean \pm SD & & \\
\hline \multicolumn{3}{|l|}{ Gender } \\
\hline Male & 62 & 62.0 \\
\hline Female & 38 & 38.0 \\
\hline \multicolumn{3}{|l|}{ Residence } \\
\hline Rural & 55 & $\mathbf{5 5 . 0}$ \\
\hline Urban & 45 & 45.0 \\
\hline \multicolumn{3}{|l|}{ Marital status } \\
\hline Single & 14 & 14.0 \\
\hline Married & 80 & 80.0 \\
\hline Divorced & 2 & 2.0 \\
\hline Widowed & 4 & 4.0 \\
\hline \multicolumn{3}{|l|}{ Educational level } \\
\hline Read \& write & 8 & 8.0 \\
\hline Basic education & 16 & 16.0 \\
\hline Secondary education & 60 & 60.0 \\
\hline University education & 16 & 16.0 \\
\hline \multicolumn{3}{|l|}{ Employment } \\
\hline Working & 44 & 44.0 \\
\hline Not working & 40 & 40.0 \\
\hline Housewife & 16 & 16.0 \\
\hline \multicolumn{3}{|l|}{ Monthly income } \\
\hline Enough & 38 & 38.0 \\
\hline Not enough & 62 & 62.0 \\
\hline
\end{tabular}


Table (2):Distribution of the studied patients according to their past and current health history

\begin{tabular}{|c|c|c|}
\hline \multirow[b]{2}{*}{ Past and Current Medical and Surgical History of Patients } & \multicolumn{2}{|c|}{$\begin{array}{l}\text { The studied Patients } \\
\qquad(\mathrm{n}=100)\end{array}$} \\
\hline & $\mathbf{N}$ & $\%$ \\
\hline $\begin{array}{l}\text { Suffering from chronic diseases } \\
\text { No } \\
\text { Hypertension } \\
\text { Diabetes } \\
\text { Heart disease } \\
\text { Osteoporosis } \\
\text { Joints stiffens } \\
\text { Kidney disease } \\
\text { Chest disease } \\
\text { Chronic obstructive pulmonary disease (COPD) } \\
\text { Rheumatoid }\end{array}$ & $\begin{array}{c}0 \\
66 \\
38 \\
100 \\
2 \\
2 \\
6 \\
12 \\
20 \\
2 \\
\end{array}$ & $\begin{array}{c}0.0 \\
66.0 \\
38.0 \\
100.0 \\
2.0 \\
2.0 \\
6.0 \\
12.0 \\
20.0 \\
2.0 \\
\end{array}$ \\
\hline $\begin{array}{l}\text { Previous admission to the hospital } \\
\text { Yes } \\
\text { No }\end{array}$ & $\begin{array}{c}95 \\
5\end{array}$ & $\begin{array}{c}95.0 \\
5.0\end{array}$ \\
\hline $\begin{array}{l}\text { Taking any medication before } \\
\text { Yes } \\
\text { No }\end{array}$ & $\begin{array}{c}100 \\
0\end{array}$ & $\begin{array}{c}\mathbf{1 0 0 . 0} \\
0.0\end{array}$ \\
\hline $\begin{array}{l}\text { Past history of surgery } \\
\text { Yes } \\
\text { No }\end{array}$ & $\begin{array}{l}34 \\
66\end{array}$ & $\begin{array}{l}34.0 \\
66.0\end{array}$ \\
\hline $\begin{array}{l}\text { Type of surgery }(\mathbf{n}=\mathbf{3 4}) \\
\text { Appendectomy } \\
\text { Hernia repair } \\
\text { Tonsillectomy } \\
\text { Caesarean section }\end{array}$ & $\begin{array}{l}14 \\
10 \\
7 \\
3\end{array}$ & $\begin{array}{c}41.2 \\
29.4 \\
20.6 \\
8.8\end{array}$ \\
\hline $\begin{array}{l}\text { Family history of cardiac problems } \\
\text { No } \\
\text { Arteriosclerosis } \\
\text { Patent ductus arteriosus (PDA) } \\
\text { Angina pectoris } \\
\text { Heart attacks }\end{array}$ & $\begin{array}{c}55 \\
5 \\
4 \\
24 \\
12\end{array}$ & $\begin{array}{c}\mathbf{5 5 . 0} \\
5.0 \\
4.0 \\
24.0 \\
12.0\end{array}$ \\
\hline $\begin{array}{l}\text { The degree of kinship: }(\mathbf{n}=\mathbf{4 5}) \\
\text { Brother / sister } \\
\text { Father } \\
\text { Mother } \\
\text { Wife } \\
\text { One of sons }\end{array}$ & $\begin{array}{c}8 \\
\mathbf{1 7} \\
14 \\
4 \\
2\end{array}$ & $\begin{array}{c}17.8 \\
\mathbf{3 7 . 8} \\
31.1 \\
8.9 \\
4.4\end{array}$ \\
\hline
\end{tabular}

\# more than one answer 
Table (3): Distribution of the studied patients according to their total knowledge about heart surgeries.

\begin{tabular}{|l|c|c|}
\hline \multirow{2}{*}{ Levels of total knowledge } & \multicolumn{2}{|c|}{ The studied Patients (n=100) } \\
\cline { 2 - 3 } & $\mathbf{N}$ & $\%$ \\
\hline Satisfactory & 25 & 25.0 \\
\hline Unsatisfactory & 75 & 75.0 \\
\hline
\end{tabular}

Table (4): Distribution of the studied patients according to their total pain score at Post Open Heart Surgery $(n=100)$.

\begin{tabular}{|l|c|c|}
\hline \multirow{2}{*}{ Levels of total pain score } & \multicolumn{2}{|c|}{$\begin{array}{c}\text { The studied Patients } \\
(\mathbf{n = 1 0 0})\end{array}$} \\
\cline { 2 - 3 } & $\mathbf{N}$ & $\%$ \\
\hline No pain & 5 & 5.0 \\
\hline Mild & 23 & 23.0 \\
\hline Moderate & 56 & 56.0 \\
\hline Severe & 16 & 16.0 \\
\hline
\end{tabular}

Table (5):Distribution of the studied patients according to their total Independency in Activities of Daily Living atPre and Post Open Heart Surgery.

\begin{tabular}{|c|c|c|c|c|c|c|}
\hline \multirow{3}{*}{$\begin{array}{lrr}\text { Levels of } & \text { total } \\
\text { Independency } & \text { in } \\
\text { Activities of } & \text { Daily } \\
\text { Living } & & \\
\end{array}$} & \multicolumn{4}{|c|}{ The studied Patients $(n=100)$} & \multirow{3}{*}{$\mathbf{X}^{2}$} & \multirow{3}{*}{ p-value } \\
\hline & \multicolumn{2}{|c|}{ Pre } & \multicolumn{2}{|c|}{ Post } & & \\
\hline & $\mathbf{N}$ & $\%$ & $\mathbf{N}$ & $\%$ & & \\
\hline Full function & 62 & 62.0 & 0 & 0.0 & \multirow{3}{*}{17.99} & \multirow{3}{*}{$0.000 * *$} \\
\hline Moderate impairment & 30 & 30.0 & 5 & 5.0 & & \\
\hline Severe impairment & 8 & 8.0 & 95 & 95.0 & & \\
\hline
\end{tabular}

(**) highly statistically significant at $\mathrm{p}<0.01$. 
Table (6):Distribution of the studied patients according to their levels of total anxiety atPost Open Heart Surgery.

\begin{tabular}{|l|c|c|}
\hline \multirow{2}{*}{ Levels of total anxiety score } & \multicolumn{2}{|c|}{$\begin{array}{c}\text { The studied Patients } \\
(\mathbf{n}=100)\end{array}$} \\
\cline { 2 - 3 } & $\mathbf{N}$ & $\%$ \\
\hline Normal & 10 & 10.0 \\
\hline Minimal to Moderate & 24 & 24.0 \\
\hline Severe anxiety & 54 & 54.0 \\
\hline Extremely Severe & 12 & 12.0 \\
\hline
\end{tabular}

Table (7): Distribution of the patients according to their total social dysfunction subscales at Post Open Heart Surgery.

\begin{tabular}{|c|c|c|c|c|}
\hline \multirow{2}{*}{ Social dysfunctionsubscales } & \multicolumn{4}{|c|}{ The studied Patients (n=100) } \\
\cline { 2 - 5 } & \multicolumn{2}{|c|}{ High social dysfunction } & Low social dysfunction \\
\cline { 2 - 5 } & $\mathbf{N}$ & $\mathbf{\%}$ & $\mathbf{N}$ & \% \\
\hline Self-system & 64 & 64.0 & 36 & 36.0 \\
\hline Interpersonal system & 58 & 58.0 & 42 & 42.0 \\
\hline Performance system & 62 & 62.0 & 38 & 38.0 \\
\hline Total & 60 & 60.0 & 40 & 40.0 \\
\hline
\end{tabular}

Table (8): Correlation betweenpain score, Independency in ADL, psychological needs and Social Dysfunctionat post -Open Heart Surgery.

\begin{tabular}{|l|c|c|c|}
\hline \multirow{2}{*}{ Variables } & $\begin{array}{c}\text { Total score of } \\
\text { pain score }\end{array}$ & $\begin{array}{c}\text { Total score of } \\
\text { Independency } \\
\text { in ADL }\end{array}$ & $\begin{array}{c}\text { Total score of } \\
\text { psychological } \\
\text { needs }\end{array}$ \\
\cline { 2 - 4 } & $\mathbf{r}$ & $\mathbf{r}$ & $\mathbf{r}$ \\
$\mathbf{P}$ & & & \\
\hline Total score ofpain score & -0.408 & & \\
\hline $\begin{array}{l}\text { Total of } \\
\text { Independency in ADL }\end{array}$ & $0.000^{* *}$ & & \\
\hline $\begin{array}{l}\text { Total score of } \\
\text { psychological needs }\end{array}$ & 0.419 & -0.391 & \\
\hline $\begin{array}{l}\text { Total score of Social } \\
\text { Dysfunction }\end{array}$ & $0.000^{* *}$ & $0.000^{* *}$ & \\
\hline
\end{tabular}

(*) Statistically significant at $\mathbf{p}<0.05-(* *)$ Highly significant at $\mathbf{p}<0.01$. (r) Pearson correlation 


\section{Discussion}

Open heart surgery is an operation to repair damage in the heart. Assessing the needs for patients subjected to open heart surgery is very important to facilitate patient's recovery and helping them to cope with any health problems. The biopsychosocial (BPS) assessment was proposed as a necessary change from the biomedical model in which health was the result of the absence of disease, and where illnesses and treatment options were understood within a physiological framework $^{(15)}$.

Assessment of Bio-psychosocial needs of patient pre and post open heart surgery are very important aspect of patient centered care. This implies that all three subsystems biological, psychological and social are interrelated and interdependent and that every system exerts an effect on the other. Thus, each individual patient experiences the interplay of biological, psychological and social factors. The biological needs refer to a person's physiological processes, the psychological needs of the patient includes a person's knowledge, emotions, cognitions and beliefs, and the social needs refers to the influence of society and its values and norms on a person.Open heart surgery includes a complicated procedures that require high qualified professionals with unique skills such as coronary artery bypass, repair of damaged structures, and heart transplant, as well as other treatments such as implantation of medical devices. So the comprehensive assessment of patients needs who were undergoing open heart surgery represented a beneficial role of the professional nurse forobtaining a positive patient'soutcome ${ }^{(16-17)}$.

Discussion of the present study will focus onthe finding related todemographic characteristics of the studied patients, assessment of educational needs, and assessment of bio-psychosocial needs (physical, psychological and social needs) of studied patients.Alsocorrelation between patient needs and their total knowledge.

\section{Regarding to demographic}

characteristics of studied patients, it was revealed that less than one half of studied patients were from age of 50 to 60 years with mean age $(52.4 \pm 3.15)$. This may be due to increased life stressors even among people. This result is in accordance with Leathy \&Jada $(\mathbf{2 0 1 5})^{(\mathbf{1 8})}$, who revealed that average age of the studied sample was 40 (range 20-55). Moreover a study conducted by Amaal F et al, $\mathbf{( 2 0 1 7 )}^{(\mathbf{1 9})}$ revealed that the average age of the studied sample wasranged between 50 and 59 years with a mean age of (45.9 \pm 11.7$)$.

In relation to gender, the present study showed that, more than half of the studied patients were males this may be due to 
unhealthy life style and genetic factors that proposed that estrogen hormone protect women from cardiac disease. This finding was consistent with a study done by Dibardino et al, (2012) ${ }^{(\mathbf{1 9 )}}$ who stated that more than half of the sample were male.

Concerning residence, the current study showed that more than half of studied patients were from rural areas, this may be due to lack of health care provided, take more time to diagnosed, and low educational level in rural area. This result was in the same line with Kapwata \& Manda, (2018) ) $)^{(21)}$ who found that, when increase distance from health care facilities, the cardiovascular disease was increased and morbidity and mortality also worsen. Moreover our findings were in the same line with another study conducted by Amaal F et al, (2017) ) ${ }^{(19)}$ who revealed that majority of the studied patients were from rural area.

Regarding marital status, the present study revealed that, about three fourth of studied patients were married; this may be due to related over social and psychological stress. This finding was supported by a study done by Fredericks \& Sidani (2012) ${ }^{(22)}$ which revealed that most of samples were married.

Regarding educational level, the finding of the present study revealed that, more than half of the studied patients with secondary education that may be a cause of poor treatment adherence. This was supported by Mosleh et al,(2017) ${ }^{(\mathbf{2 3})}$ who found that about one half of sample had secondary education. Our findings contradicted with another study conducted by Amaal F et al, (2017) (19) which revealed that majority of the studied patients were illiterate. More over AbdelGhany, et al., (2016) ${ }^{(24)}$ found that nearly third of subjects were university graduates

Regarding occupation status, the finding of the present study revealed that, about near half of studied patients were employed; this may be due to increase job strain and increase stress of lack income. This was in accordance with Ferrario et al, (2017) ${ }^{(25)}$ Who reported that, higher coronary heart disease incidence rates was found among manual workers.

Regarding medical historyof studied patients, the results of the present study showed that, all of the studied patients had heart disease and near two third of studied patients had hypertension. This may be due to poor treatment adherence, genetic factor or unhealthy life style. This was in the same line with Lancellotti et al, $\mathbf{( 2 0 1 7 )}^{(26)}$ who reported that, most of subjects complain of CHD and minority valvular heart disease. Moreover a study conducted by Bassand et al, (2018) ${ }^{(27)}$ found that, about two thirds of patients had hypertension. 
Regarding to educational needs about open heart surgery among studied patients, the present study found that, three-quarters of the studied patient had unsatisfactory level of total knowledge about heart surgeries. While, one-quarter of them had satisfactory level of total knowledge about heart surgeries, this is may be due to more than half of studied patients with secondary education and resident in rural area, this was in the same line with Mosleh et al, (2017) $)^{(23)}$ who found that, the major needs of patients are education about wound care, medication and post intervention complication.

\section{Regarding chest pain of patients} undergoing open heart surgery, the present study showed that, there was a marked increase in patients' pain level at post heart surgery. This may be due to post-operative surgical wound at chest and leg. This was in the same line with Ziehm et al, (2017) $^{(28)}$ Moreover Ballan \& Lee,(2007) ${ }^{(29)}$ they found that, patients reported higher levels of pain postoperatively compared to pre-operative levels.

Our findings were contradicted with another study conducted by Khalil NS et al, (2018) (30) who revealed thatUtilize lavender oil inhalation in the early days of open heart surgery to decrease the consumption of opioids and analgesics.

Regarding activity of daily living, the present study revealed that, there was a marked increase in total patients' dependency in activities of daily living level include bathing, dressing, toileting, transferring, continence, and feeding at post heart surgery. This may be due to pain and patients' general condition after operation, also may be due to clinical health state associated with open heart surgery, loss of blood, and electrolytes imbalance on bypass machine.

This was supported by van Laar et al , $(\mathbf{2 0 1 7})^{(31)}$ who found that there is a decreased in physical activity postoperative as compared to before operation up to less than half of the samples. Moreover Kulik et al, (2017) ${ }^{(32)}$ reported that patients after operation had an increase in physical limitation (increased body pain, reduced general health and physical activity) as compared to before operation.

Regarding level of anxiety of studied patients pre and post the operation, the present study revealed that, it was observed that, there was a marked increase in patients' fear of the uncertain future stressors at post heart surgery. This may be due to lack of knowledge about open heart surgery and lack of pre-operative psychological preparation. Alsothe emotional state is closely associated withphysical health status and experienceof pain intensity ${ }^{\left({ }^{(3)} \text {.This was }\right.}$ supported by Gallagher \& McKinley, 
(2013) ${ }^{(34)}$ who stated that there was an increase in level anxiety up to half of sample after operation as compared to before operation. Moreover this was supported by Tully \& Baker, (2012) ${ }^{(35)}$ who reported that increased number of patients after operation affected with depression up to half of samples as compared to before operation.

\section{Regarding total psychological needs of}

studied patients pre and post the operation the present study revealed that there was a marked increase in total patients' psychological needs at post heart surgery. This may be due to pain, patients' connection and deficient knowledge regarding open heart surgery. This was supported by Roohafza et al, (2015) ${ }^{(\mathbf{3 6})}$ who reported that there was an increased psychological alterations after operation as compared to before operation.

Regarding to social dysfunction of studied patients, the present study found that, more than half of the studied patient always do not participate in community activities and don't care about community affairs or activities that affect others post heart surgery. This may be due to delayed recovery or poor treatment adherence. This was supported by Spaderna et al, $\mathbf{( 2 0 1 7}^{(\mathbf{3 7})}$ who stated that, less than two thirds of study had social isolation after operation as compared to before operation.

Concerning social dysfunction there was highly significant positive correlation between total social dysfunction of the studied patients and total score of psychological needs at $(\mathrm{P}=<0.01)$. This mean that increased psychological needs due to increased insight about open heart surgery associated with increased social dysfunction of the studied patient. This finding was supported by Shamaskin et al, (2012) $^{\text {(38) }}$ who revealed that theincreased mean of social dysfunction was associated with increasing need for psychological support. Also, in the same line this result was supported by Areias et al, (2021) $)^{(39)}$ they found that male patients had low quality of life than female.

Routine pre and post-operative assessment of patients undergoing open heart surgery is essential to identify and reduce stressors and improve the postoperative out outcome. Furthermore, pre and post-operative patients' education should be incorporated into routine nursing practice to reduce anxiety and reduced the post-operative complications.

\section{Conclusion: -}

Based on the findings of the present study, it can be concluded that it was observed that, three-quarters of the studied patient had unsatisfactory level of total knowledge about heart surgeries. While, one-quarter of them had satisfactory level of total knowledge about heart surgeries. Also, it was observed that, there was a marked increase in total patients' dependency in 
Activities of Daily Living level at post heart surgery.

In addition, more than half of the studied patients had moderate level of total pain score and had severe level of total anxiety score at post Open Heart Surgery. While, three fifth of the studied patients had high level of social dysfunction at post Open Heart Surgery.

\section{Recommendations: -}

\section{Recommendations geared toward patients:}

-Routine pre and postoperative assessment of patients who are undergoing open heart surgery is recommended to identify the different patient's bio-psychosocial needs and consequently any risk factor and reduced the post-operative complications.

-The pre and post-operative patients' education should be incorporated into routine nursing practice to reduce anxiety and improve the patient's post-operative outcome.

\section{Recommendations geared toward future researches:}

-Based on the current study finding it was recommended that further researches are needed to be replicated at various time points and on larger sample to understand the nature of relationships between studied variables and their relationship with recovery after open heart surgery.

\section{References}

1. Gopaldas R, Chu D, Bakaeen F. Acquired Heart Disease: Coronary insufficiency. Sabiston textbook of surgery. 19th ed. Philadelphia. Saunders Co. Elsevier. 2012; 60(13):31-38.

2. Kristy S. Expectations, Anxiety, Depression, and Physical Health Status as Predictors of Recovery in OpenHeart Surgery Patients. Journal of Cardiovascular Nursing.2009; 24(6):454-64.

3. Myra F. Neurologic Complications. Cardiac Surgery Essentials for Critical Care Nursing J. 2010; 16:323-37.

4. George $J$ and William A. Prevention of Neurologic Injury after Coronary Artery Bypass. Mastery of cardiothoracic surgery. 3thed. Lippincott Williams \& Wilkins. 2014;39:390-95.

5. Susan L, Erika S and Motzer S. cardiac Nursing (Woods). 6th ed. Philadelphia. Saunders Co. Elsevier. 2008; 12:113-19.

6. American heart association (AHA): Executive Summary: Heart Disease and Stroke Statistics. 2015. Avilable at: http://circ.ahaj.eurnals. org.

7. Stromberg H. Dewitt's Medical-Surgical Nursing E-Book: Concepts, Practice. Elsevier Health Sciences, U.S.A. 2021: 95-122.

8. University of Wisconsin Hospitals and clinics. Exercise and Activity after Heart Surgery.2014. Available from:https://www.uwhealth.org /health facts/ cardiology/5801. 
9. Galer $\mathrm{J}$ and Gammaiton I. Pain assessment in clinical trials. Evidence outcomes and quality of life in pain treatment. Amsterdam. Elsevier. 2003.

10. Katz S. Assessing Self-maintenance. Activities of daily living. Mobility and instrumental activities of daily living. JAGS.2007;31(12):721-26.

11. Granger C, Albrecht G, Hamilton B. Outcome of comprehensive medical rehabilitation. Measurement by pulses profile and the barthel index. Arch Phys Med Rehabil. 1979; 60:145-54.

12. Zung W. A rating instrument for Anxiety . Consult pharm.1996;11(4):1-2.

13. Ian M. Social Health. Measuring Health: A Guide to Rating Scales and Questionnaires. 3thed. Oxford University Press. 2006:164-98.

14. Gerstman B. Basic biostatistics, Statistics for public health practice. 3rd ed. Canada: Jones and Bartlet publisher Co. $2011 ; 161-218$.

15. Emre K. A new heart surgery clinic: Open Heart Surgery Outcomes at Karabuk Training and Research Hospital: Assessment of the first year. Med Science.2017.201;1-7.

16. Smith A, Fortin A, Dwamena A \&Frankel A. An evidence-based patient-centered method makes the biopsychosocial model scientific. Patient Education and Counseling. 2013; 91(3):265-70.
17. Mokbel, Naiera Abd El Samad Ibrahim, Yosreah Mohamed Mohamed, and Rasha Mohamed Elmotoly. "Biopsychosocial needs of patient after Liver transplantation during follow up period." Egyptian Journal of Health Care 11.1 (2020): 127-141.

18. Leathy \& Jada M. Effects of cardiac surgery on duty status in the active duty military population. Military medicine J.2015:180(7): 798-802.

19. Amal F, Makled B, Mahmoud A, Saleh G. Stressors encountered by patients undergoing open-heart surgery at a Cairo University Hospitals. The Egyptian Journal of Medical Microbiology. 2017; 38 (5781):1-10.

20. Dibardino D, Pasquali S, Hirsch J, Benjamin D,Kleeman K, Salazar J. Effect of sex and race on outcome in patients undergoing congenital heart surgery: an analysis of the society of thoracic surgeons congental heart surgery database. The anal thoracic surgery J. 2012;94(6):2054-60.

21. Kapwata T\& Manda S. Geographic assessment of access to health care in patients with cardiovascular disease in South Africa. BMC Health Services Research J. 2018;18(1):197.

22. Fredericks S \& Sidani S. The impact of socio-demographic characteristics and health profile on self-care behaviors after heart surgery. British Journal of 
nursing, Available at:

https://www.magonlinelibrary.com/

doi/abs/10.12968/bjca. 2012;7(2):77.

23. Mosleh S, Eshah N, Almalik M. Perceived learning needs according to patients who have undergone major coronary interventions and their nurses. Journal of clinical nursing. 2017; 26(34): 418-26.

24. Abdel-Ghany, S., Soliman, S. and Abdel-Raoof, S., (2016): Knowledge and Daily Living Activities of Post Liver Transplant Clients. IOSR Journal. Vol 5.PP 56-64.Avaliable at: www.iosrjournals.org DOI: 10.9790/1959-0505035664. Accessed on 12-Sep.2017).

25. Ferrario M, Veronesi G, Bertu L, Grassi G, Cesana G. Job strain and the incidence of coronary heart diseases: does the association differ among occupational classes? A contribution from a pooled analysis of Northern Italian cohorts. BMJ open, 2017;7(1):114-19.

26. Lancellotti P, Ancion A, Pierard L. Cardiac rehabilitation, state of the art 2017. Revue medical de Liege. 2017;72(11):481-487.

27. Bassand A, Kaunonen M, Sintonen H, Koivisto A. Factors associated with health related quality of life in patients. Journal of clinical nursing. 2018; 17(13): 1742-53.
28. Ziehm S, Rosendahl J, Barth J, Strauss, Mehnert A, Koranyi S. Psychological interventions for acute pain after open heart surgery. Cochrane Database of Systematic Reviews, 7:CD009984. DOI: https://doi.org/10.1002/14651858. CD009984.pub3. 2017.

29. Ballan A \& Lee G. A comparative study of patient perceived quality of life pre and post coronary artery bypasses graft surgery. Australian Journal of advanced Nursing. 2007;24(4):24.

30. Khalil N, Manal S, Sherine A, and Shawky H. Effects of lavender oil inhalation on sternotomy related pain intensity in open heart surgery patients in Egypt. Clinical practice.2018;16 (1):1005-10.

31. Van Laar C, Timman S, Noyez L. decreased physical activity is a predictor for a complicated recovery post cardiac surgery. Health and quality of life outcome J. 2017;15(1):5.

32. Kulik A. Quality of life after coronary artery bypass graft surgery versus percutaneous coronary intervention: what do the trials tell us?. Current opinion in cardiology. 2017;32(6): 707-14.

33. Hariharan, Meena, Usha Chivukula, and Suvashisa Rana. "The intensive care unit psychosocial care scale: Development and initial validation." Intensive and Critical Care Nursing 31.6 (2015): 343-351. 
34. Gallagher R \& McKinley S. Anxiety, depression and perceived control in patients having coronary artery bypass grafts. Journal of advanced nursing. 2013;65(11):2386-96.

35. Tully P \& Baker R. Depression, anxiety, and cardiac morbidity outcomes after coronary artery bypass surgery: a contemporary and practical review. Journal of geriatric cardiology. 2012;9(2):197.

36. Roohafza H, Sadeghi M, Khani A, Andalib E, AliKhasi H, Rafiei M. Psychological state in patients undergoing coronary artery bypass grafting surgery or percutaneous coronary intervention and their spouses. International journal of nursing practice. 2015;21(2):214-220.

37. Spaderna H, Zittermann A, Reichenspurner H, Ziegler C, Smits J, Weidner G. Role of depression and social isolation at time of wait listing for survival 8 years after heart transplantation. Journal of the American Heart Association. 2017;6(12),e007016. 38. Shamaskin A, Rybarczyk B, Wang E, White-walliams C, McGree E, Cotts W \& Grady K. Older patients (age 65+) report better quality of life, psychological adjustment, and adherence than younger patients 5 years after heart transplant: A multisite study.
The journal of heart and lung transplantation. 2012;31(5):478-84.

39. Areias M, Pinto C, Vierira $P$, Castro $M$, Feeitas I, Sarmento S , Arieas J. Living with CHD: quality of life in early adult life. Cardiology in the young. 2021;24(2):60-65. 